Proceedings

\title{
Ecosystem Services Multifunctionality: an analytical framework to support sustainable spatial planning. Insights from the Italian case study
}

Angela Pilogallo ${ }^{1, *}$ and Francesco Scorza ${ }^{2}$

1 University of Basilicata; angela.pilogallo@unibas.it

2 University of Basilicata; francesco.scorza@ unibas.it

* Correspondence: angela.pilogallo@unibas.it

Citation: Pilogallo, A.; Scorza, F. 2022, Ecosystem Services Multifunctionality: an analytical framework to support sustainable spatial planning. Insights from the Italian case study. SUPTM 2022 conference proceedings sciforum054409 .

https://doi.org/10.31428/10317/10492

Publisher's Note: UPCT and Sciforum stays neutral with regard to jurisdictional claims in published maps and institutional affiliations.

Copyright: (c) 2022 by the authors. Submitted for possible open access publication under the terms and conditions of the Creative Commons Attribution (CC BY) license (https://creativecommons.org/license s/by/4.0/).

\begin{abstract}
At different levels of territorial governance, there is a growing need for tools to support policy-making oriented towards sustainable planning. The Ecosystem Services (ES) methodological framework represents a structured dimension to develop tools for the assessment of environmental performances and for the evaluation of territorial transformations linked to development needs. In particular, we propose an analytical framework applied to the Italian National context based on the ES multifunctionality approach, to be intended as the opportunity to consider the joint provision of multiple ES. The results highlight its potential to support decision-making processes and formulate recommendations for sustainable spatial planning.
\end{abstract}

Keywords: Ecosystem Services (ES), ES Multifunctionality, Sustainable spatial planning, Decision Support System (DSS)

\section{Introduction}

The challenge to which planners are called is to orient land use and development processes in a way better meeting several territorial demands linked to the needs of society, the maintenance of environmental quality, the protection of biodiversity as well as the increasingly compelling issues of adaptation and mitigation to climate change. At different levels of governance, the need for tools to support policy-making oriented to sustainable planning arises and, in this regard, the Ecosystem Services (ES) approach represents a structured dimension where to develop tools for the assessment of environmental performances. In particular, the multifunctionality approach, intended as the possibility of considering the joint supply of multiple ES, is promising. In fact, it allows to explain synergies and trade-offs, to address the issue of fair distribution of costs and benefits by different stakeholders, to compare scenarios from a perspective of rationality and efficiency, to improve consistency between context-based measures and global instances.

In order to make ES multifunctionality more relevant for spatial planning, we propose an analytical framework to the Italian National context which describes and illustrates several dimensions of ES multifunctionality: abundance, richness and diversity. The results highlight its potential as a robust analytical framework to support decision-making processes and formulate recommendations for sustainable spatial planning.

\section{Area of study}

The analytical framework of ES multifunctionality was applied to the entire Italian territory, considering NUTS3 areas as reference territorial units. According to the Italian 
Institute for Environmental Protection and Research (ISPRA) [1], the study area is 1 characterized by marked criticalities in terms of land take trends, especially in peri-urban and urban areas, where artificial surfaces are increasing to the detriment of natural and semi-natural areas. A further critical point is the infrastructure system, which contributes to the degree of fragmentation due to urban growth processes. Such anthropization phenomena mainly concern coastal and lowland areas [2]. At the same time, in the inland areas along the Apennine Chain, the processes of depopulation and marginalization are incessant, leading to significant land abandonment.

The inefficiency of the Italian planning system in governing and monitoring these urbanization processes and the intensification of human activities that threaten natural ecosystems [3], have led to an overall depletion of ES and a decrease in ES multifunctionality [4].

\section{Methodology}

The proposed methodology aims to illustrate the three dimensions of multifunctionality (abundance, richness and diversity) following the conceptualization of Holting et al. [5].

Abundance represents the intensity of simultaneous delivery of multiple ES. As different ES supply indices use different metrics, these supplies are typically normalized. In this study we assumed as abundance indicator the Multiple Ecosystem Services Landscape Index (MESLI) [6], considered effective in providing a comprehensive overview of environmental performances [7] and suitable for different assessment scales [8].

Richness represents the ability of an ecosystem to deliver more than one ES at the same time [9] and it is usually calculated as the number of ES delivered in the territorial unit. For reasons related to the scale of data aggregation (NUTS3), in this work we chose to consider a threshold value, i.e. to consider only the number of ES exceeding the first quartile of the national data distribution.

Diversity combines the concepts of richness and abundance by considering the intensity of each ES' supply as proportionally to the total provision. It therefore provides information on the uniformity of provision across several ES or the dominance of a specific ES over others. For this work, we used the Simpson's reciprocal index [10], widely used as an ES multifunctionality indicator to evaluate whether ES are equally supplied or whether a few dominant ones exist [11].

These indices were calculated on the basis of the ES considered most relevant for the entire national territory (Table 1), assessed and mapped in biophysical terms and then aggregated by NUTS3 territorial units.

In order to outline a trend of ES multifunctionality over the last decades, they were calculated for the years 2000 and 2018.

Table 1. Indicators, methods and units used to quantify different ES.

\begin{tabular}{cccc}
\hline Class & Indicators & Methods & Unit \\
\hline Regulation of chemical composition of atmosphere & Carbon stock & InVEST & Tons/Ha \\
& CO2 Uptake & Eq. by Clark & $\mathrm{g} / \mathrm{m}^{2} / \mathrm{yr}$ \\
Pollination & Pollination Abundance & InVEST & Index \\
Maintaining nursery populations and habitats & Habitat Quality & InVEST & Index $^{* *}$ \\
Control of erosion rates & Erosion Rates & InVEST & Tons/Ha \\
Regulation of the chemical condition of freshwaters & Effective nutrients retention & InVEST & Index \\
Cultivated terrestrial plants grown for nutritional purposes & Crop production & InVEST & $\mathrm{q} / \mathrm{Ha}$ \\
Ground (and subsurface) water for drinking & Water Yield & Eq. by Budyko & $\mathrm{mm} / \mathrm{yr} / \mathrm{Ha}$
\end{tabular}




\section{Results}

The comparison of the three indices of ES multifunctionality supports the analysis of the relationships between the anthropic components of territorial systems and the capacity of ecosystems to deliver ES.

The distribution of the abundance index highlights the importance of mountainous and mostly wooded areas, mainly located along the Apennine Chain and the Alps. In both years considered, the lowest values are observed along the Po Valley and in the southern provinces of Apulia and Sicily. The richness index confirms what has been described by MESLI, highlighting in an even more marked way the contribution of ES in the central Apennines and in the Province of Potenza (Southern Italy), where are located the Appennino Lucano - Val d'Agri - Lagonegrese and the Pollino National Parks - totally one, partially the other. Simpson's index, illustrates diversity as a measure of the balance between the different ES provided. Where it takes high values, the level of delivery among individual ES is evenly distributed. Where it is lowest, a small number of ES dominate the total. This, in the Italian context, occurs in correspondence of the most densely populated Provinces or in correspondence of the main metropolitan areas. Here, in fact, the contribution of ES relating to agricultural productivity and the control of erosive processes is markedly prevalent over the overall value.

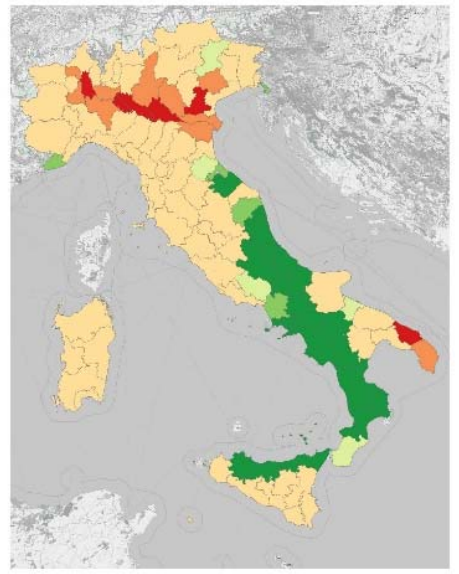

(a)

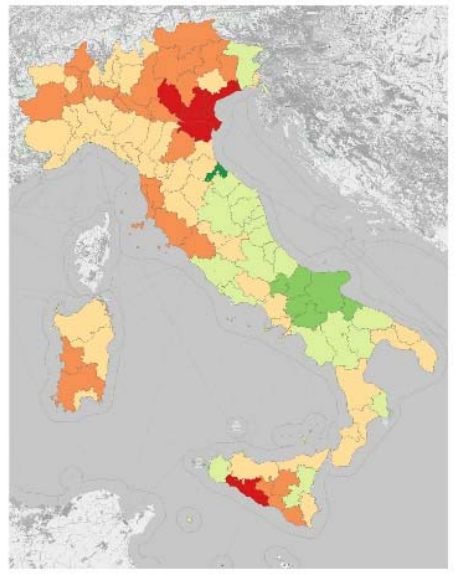

(b)

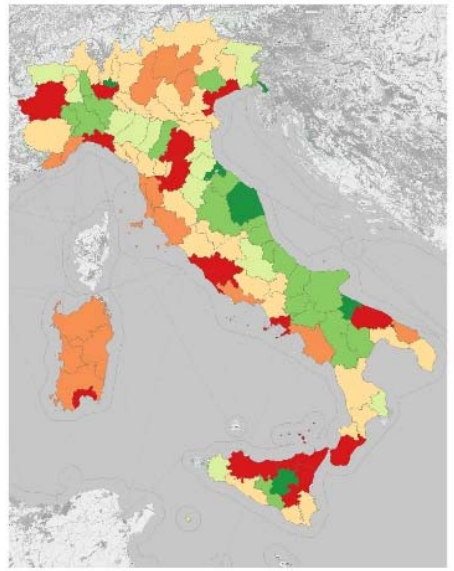

(c)

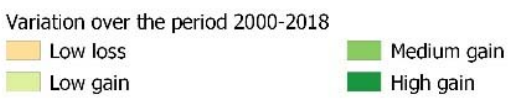

Figure 1. Variations in the three dimensions of ES Multifunctionality over the period 2000-2018: (a) 20 Abundance (MESLI); (b) Richness; (c) Diversity (Simpson's reciprocal index)

Land use changes and new urbanization processes between 2000 and 2018 have exacerbated existing differences in the spatial distribution of ES multifunctionality. In fact, as can be seen from Figure 1, the indices of abundance and richness have increased along the Apennine areas of central and southern Italy. The provinces located along the Po Valley are instead characterized by a decrease in both abundance and richness, thus widening the existing ES supply gap between the most industrialized territories and the inner areas of the Apennine Chain. In contrast, the diversity index has undergone spatially more heterogeneous changes, decreasing with greater intensity along the Tyrrhenian coast and in correspondence with the main metropolitan areas.

\section{Conclusions}

Assessing multifunctionality as the joint provision of multiple ES is considered an innovative and integrated way to study the effects of different land use patterns and the multiple components of human well-being $[6,13]$. A better understanding of the spatial distribution of ES multifunctionality, considering its different dimensions, could help 
predict where and how specific governance policies or territorial transformations might 1 affect ES supply and consequently the ability of ecosystems to cope with multiple human needs.

In this work, we propose an analytical framework based on ES abundance, richness and diversity, constituting three different dimensions of ES multifunctionality. Our results confirm the relevance of the proposed approach in illustrating the effects of complex transformation dynamics on ES provision and in identifying strategies to reduce impacts and maximize synergies.

Funding: This research received no external funding

Conflicts of Interest: The authors declare no conflict of interest.

\section{References}

1. ISPRA, Quarto Rapporto Sullo Stato Del Capitale Naturale In Italia; 2021;

2. Romano, B.; Zullo, F. Half a century of urbanization in southern European lowlands: a study on the Po Valley (Northern Italy). Urban Res. Pract. 2016, 9, 109-130.

3. Muzzillo, V.; Pilogallo, A.; Saganeiti, L.; Santarsiero, V.; Scorza, F.; Murgante, B. Impact of Renewable Energy Installations on Habitat Quality; Springer, Cham, 2020; Vol. 12253 LNCS, pp. 636-644;

4. Pilogallo, A.; Saganeiti, L.; Scorza, F.; Las Casas, G. Tourism Attractiveness: Main Components for a Spacial Appraisal of Major Destinations According with Ecosystem Services Approach. In; Springer, Cham, 2018; pp. 712-724.

5. Hölting, L.; Jacobs, S.; Felipe-Lucia, M.R.; Maes, J.; Norström, A. V.; Plieninger, T.; Cord, A.F. Measuring ecosystem multifunctionality across scales. Environ. Res. Lett. 2019, 14, 124083.

6. Rodríguez-Loinaz, G.; Alday, J.G.; Onaindia, M. Multiple ecosystem services landscape index: A tool for multifunctional landscapes conservation. J. Environ. Manage. 2015, 147, 152-163.

7. Pilogallo, A.; Scorza, F.; Murgante, B. An Ecosystem Services-Based Territorial Ranking for Italian Provinces. Lect. Notes Comput. Sci. (including Subser. Lect. Notes Artif. Intell. Lect. Notes Bioinformatics) 2021, 12955 LNCS, 692702.

8. Stürck, J.; Verburg, P.H. Multifunctionality at what scale? A landscape multifunctionality assessment for the European Union under conditions of land use change. Landsc. Ecol. 2017, 32, 481-500.

9. Manning, P.; Van Der Plas, F.; Soliveres, S.; Allan, E.; Maestre, F.T.; Mace, G.; Whittingham, M.J.; Fischer, M. Redefining ecosystem multifunctionality. Nat. Ecol. Evol. 2018, 2, 427-436.

10. Simpson, E.H. Measurement of Diversity. Nat. 19491634148 1949, 163, 688-688.

11. Plieninger, T.; Dijks, S.; Oteros-Rozas, E.; Bieling, C. Assessing, mapping, and quantifying cultural ecosystem services at community level. Land use policy 2013, 33, 118-129.

12. Roy Haines-Young, by; Potschin, M. Common International Classification of Ecosystem Services (CICES) V5.1 Guidance on the Application of the Revised Structure; 2018;

13. Queiroz, C.; Meacham, M.; Richter, K.; Norström, A. V.; Andersson, E.; Norberg, J.; Peterson, G. Mapping bundles of ecosystem services reveals distinct types of multifunctionality within a Swedish landscape. Ambio 2015, 44, 89-101. 